\title{
On the Design of $2 \times 2$ Element Fractal Antenna Array using Dragonfly Optimization
}

\author{
Ashwini Kumar \\ Sant Longowal Institute of Engineering and \\ Technology, Longowal, Sangrur, Punjab, India
}

\author{
Amar Partap Singh Pharwaha \\ Sant Longowal Institute of Engineering and \\ Technology, Longowal, Sangrur, Punjab, India
}

\begin{abstract}
Present-day wireless communication requires high performance antenna systems having conformal shape, aerodynamic profile, compact size, uncomplicated design and simple manufacturability. Moreover, such systems should be lighter in weight as well as cost effective too. In case of fixedsatellite communication as well as maritime radio-navigation, the situation becomes even more demanding in respect of these requirements. However, to meet these requirements, printed micro-strip patch technology is used frequently in these days for the fabrication of such high performance antenna systems. However, printed microstrip antennas usually suffer from the drawbacks of having lower gain and/or lower bandwidth as well as return loss. In order to address these issues, the present paper reports on the design of a small-sized 2×2 Element Sierpinski Carpet Fractal Antenna Array using swarm-inspired Dragonfly Optimization. Proposed antenna array operates efficiently at $5.6 \mathrm{GHz}, 7.4$ $\mathrm{GHz}$ and $10.7 \mathrm{GHz}$ with an achievement of $202 \mathrm{MHz}$, $470 \mathrm{MHz}$, and $883 \mathrm{MHz}$ bandwidths respectively for the specified spectrum bands. In order to bring about substantial improvement in the performance of the designed antenna array, Dragonfly Optimization is executed in combination with Polynomial Curve-fitting method for optimizing three different geometrical dimensions of unit antenna element in the proposed system. The results of present study are quite promising.
\end{abstract}

\section{Keywords}

Microstrip, antenna, fractal, dragonfly, optimization, sierpinski carpet geometry and patch.

\section{INTRODUCTION}

A typical micro-strip patch antenna consists of two metal plates, one in the form of a radiating patch and other as a ground plane, separated by a dielectric substrate. A number of geometrical shapes are feasible for these two plates. However, such antennas are fed with different types of feeding techniques including micro-strip line feed, coaxial feed, aperture coupling and proximity coupling $[1,2]$. Micro-strip feed line is used extensively in the design of these antennas either in the form of an inset-feed or an edge-feed [3, 4]. Similarly, different types of dielectric substrates have different dielectric constants which influence geometrical dimensions as well as performance parameters of the microstrip patch antenna. Further, thickness of substrate also affects the bandwidth and efficiency of the microstrip antenna, however, it can be a cause for the generation of surface wave that may in turn cause loss of power [5, 6]. A lot of trade off is required to be executed while arriving at appropriate design keeping into view above mentioned requirements while maintaining an acceptable level of performance. Thus, design of a micro-strip patch antenna itself is viewed as a highly complex multidimensional optimization problem. In addition to this, the effect of cross-coupling between different microstrip patch antenna in multi-element array makes the situation further highly complex as well as challenging too. The terse review of literature revealed that the design of a two elements coaxial continuous transverse stub-array with omnidirectional radiation pattern is reported [7] for C-band with improved performance in terms of efficiency as well as gain. The said antenna operates only at $5.18 \mathrm{GHz}, 6.536 \mathrm{GHz}$ and $7.42 \mathrm{GHz}$. Another reconfigurable micro-strip antenna is reported for $2.5 \mathrm{GHz}, 5.5 \mathrm{GHz}$ and $7.5 \mathrm{GHz}$ for $\mathrm{Wi}-\mathrm{Fi}$, Bluetooth, Wi-Max, satellite and maritime radar applications [8]. However, the operation is not feasible at $10.7 \mathrm{GHz}$ with these two available designs. The design of a flexible Yagi microstrip patch antenna is also detailed in the work at [9] which is designed using multilayer substrate having a size of $100 \times 92.8 \mathrm{~mm}$ for fixed-satellite, radiolocation, amateursatellite service applications. It is again observed that the antenna has a multilayer complicated structure. The analysis of microstrip antenna array is done in the work at [10], which is embedded on composite laminate substrate. Many of the antenna array configurations including $1 \times 2,1 \times 4,1 \times 8$ linear array and, $2 \times 2,2 \times 4$ planar array are discussed to get better directivity. However, due to use of composite laminate substrate, the antenna design is a costlier affair as such composite laminate are not readily available. Thus, there is an urgent need to have antenna systems confirming to the requirements of conformal shape, aerodynamic profile, compact size, uncomplicated design, simple manufacturability, lighter and cost effective.

Introduction of a wide variety of fractal geometries in microstrip printed technology is a promising solution for reducing physical dimensions of the antenna systems with multi-band operation having acceptable level of performance. According to Cambridge dictionary, a fractal is a convoluted pattern in mathematics constructed from simple reduplication of shapes that are reduced in size every time the shape is repeated. Microstrip printed patch technology also facilitates easy fabrication of a wide variety of fractal geometries for radiating patch as well as ground plane of the antenna. There is a large number of natural as well as man-made fractal geometries but for the design of microstrip patch antennas, most commonly used fractal geometries include sierpinski triangle, sierpinski gasket, sierpinki carpet, minikowaski curve, Koch curve and Hilbert curve. However, in the present paper, use of Sierpinski Fractal Carpet Geometry is exploited due to its simple design as well as easily controllable parameters. Further, fractals can be categorized into two main categories-deterministic fractal and random fractal. Sierpinski carpet fractal is a plane fractal falling in the category of deterministic fractals, which was first described by Waclaw Sierpinski as a generalized form of cantor set in two dimensions. Similarly, a modified square patch Sierpinski fractal antenna fed with microstrip-line is reported for ultra-wide band (UWB) with band notch characteristics [11]. The realization of band rejection is 
achieved in the said design by using an $\cap$-slot in the feed line. However, the said design is also not suitable for its operation at $5.5 \mathrm{GHz}(5-6 \mathrm{GHz})$ for maritime radio navigation. A fractal shape antenna with u-shape slot is also presented in the work at [12], which can be used for the W-LAN, GSM, Radio satellite, Fixed Satellite Services and satellite communication systems and reflects the effective use of U-slot in ground and radiating element. Thus, it is observed that none of the above designs reported so far in the literature cover the operation for all the three resonating frequencies at $5.6 \mathrm{GHz}, 7.4 \mathrm{GHz}$ and 10.7 in a single antenna system, which are used typically for satellite communication as well as marine radio-navigation. Accordingly, after having a terse review of the relevant literature, as detailed, the proposed design is conceived. However, a good sight has been provided by the preceding review of the available situation in the literature that has lead the authors of the present paper to arrive at the proposed final design.

\section{DESIGN OF THE PROPOSED FRACTAL ANTENNA ARRAY}

A number of different parameters of antenna array are discussed and analyzed [13] including radiation pattern, gain and directivity. Similarly, many of other facets of antenna arrays have also been discussed thoroughly [14], however, without including too much of mathematical as well as analytical explanations. Both these designs provided the authors of the present paper with a good insight into the design of proposed antenna array in the present work. The unit element of the proposed fractal antenna array is designed on the architecture of conventional rectangular micro strip patch antenna (CRMPA) using sierpinski carpet fractal geometry to achieve triple band operation at $5.5 \mathrm{GHz}, 7.5 \mathrm{GHz}$ and $10 \mathrm{GHz}$ resonating frequencies for C-band and X-band applications. The CRMPA is designed using $1.6 \mathrm{~mm}$ thick FR4 substrate with dielectric constant of 4.4 and loss tangent of 0.02. To match the impedance of patch antenna, a microstrip feed line of $\lambda / 4$ length is used. The proposed design is made using edge-feed because it is easy to fabricate and at the same time, ensures good impedance matching. The geometry of the CRMPA is illustrated in Fig.1 (a) and optimized conventional sierpinski carpet fractal antenna (CSCFA) with modified feed position is illustrated in Fig.1 (d), whereas its different geometrical dimensions are indicated in Table 1.

TABLE 1. Parametric value of CRMPA and CSCFA

\begin{tabular}{|l|l|l|l|}
\hline Parameter & Value (mm) & Parameter & Value (mm) \\
\hline $\mathrm{W}_{\mathrm{p}}$ & 12.1716 & $\mathrm{~T}$ & 2.8719 \\
\hline $\mathrm{L}_{\mathrm{p}}$ & 8.8846 & $\mathrm{U}$ & 2.8719 \\
\hline $\mathrm{L}_{\mathrm{qw}}$ & 4.8 & $\mathrm{~V}$ & 2.2562 \\
\hline $\mathrm{L}_{\mathrm{f}}$ & 5 & $\mathrm{X}$ & 1.3524 \\
\hline $\mathrm{W}_{\mathrm{qw}}$ & 0.76 & $\mathrm{Y}$ & 0.9573 \\
\hline $\mathrm{W}_{\mathrm{f}}$ & 3 & $\mathrm{Z}$ & 2.7048 \\
\hline $\mathrm{S}$ & 4.0572 & $\mathrm{M}$ & 1.9146 \\
\hline
\end{tabular}

\subsection{Development of the CSCFA with modified feed position:}

The dimensional parameters of the CRMPA are computed using equations (1-3) reported in the work at [5]. Further the CFCSA is simulated using these equations in HFSS environment. Accordingly, computation of width of the patch $\left(\mathrm{W}_{\mathrm{p}}\right)$ is estimated using equation (1) and effective dielectric constant is computed from equation (2). Similarly, computation of actual length of the patch $\left(\mathrm{L}_{\mathrm{p}}\right)$ is arrived at by using equation (3), whereas its length extension is calculated from equation (4). These equations are detailed below:

$$
\begin{gathered}
W_{p}=\frac{c}{2 f_{r}} \sqrt{\frac{2}{\varepsilon_{r}+1}} \\
\varepsilon_{e f f}=\frac{\varepsilon_{r}+1}{2}+\frac{\varepsilon_{r}-1}{2}\left(\frac{1}{\sqrt{1+\frac{12 h}{W_{p}}}}\right)
\end{gathered}
$$

$L_{p}=L_{e f f}-2 \Delta L$

Where $L_{e f f}=\frac{c}{2 f_{r}} \sqrt{\frac{2}{\varepsilon_{r}+1}}$

$$
\frac{\Delta L}{h}=0.412 \frac{\left(\varepsilon_{e f f}+0.3\right)\left(\frac{W_{p}}{h}+0.264\right)}{\left(\varepsilon_{e f f}-0.258\right)\left(\frac{W_{p}}{h}+0.8\right)}
$$

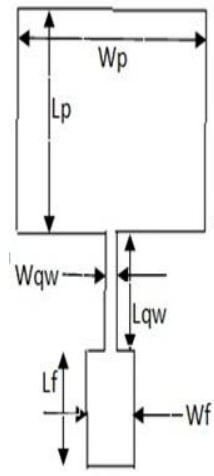

(a)

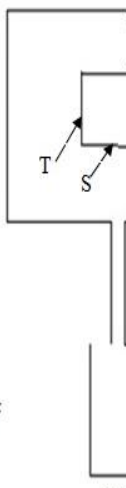

(b)

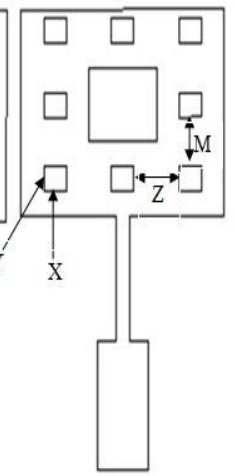

(c)

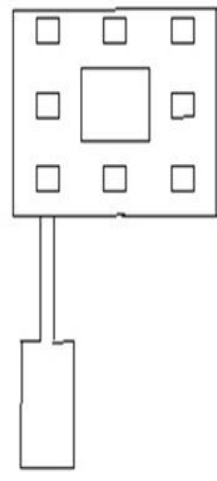

(d)
Fig 1: (a) CRMPA with design parameters (b) $1^{\text {st }}$ iteration of sierpinski fractal antenna (c) $2^{\text {nd }}$ iteration of sierpinski fractal antenna (d) optimized $2^{\text {nd }}$ iteration of sierpinski fractal antenna.

To reproduce basic fractal geometry, IFS is used efficiently in the present work. A set of relative changes models the IFS for its reproduction. The conversion for different iteration is accomplished using equation (5), where $a, b, c, d$, e and $f$ are real numbers which control the rotation, scaling and linear conversion respectively.

$W\left(\frac{X}{Y}\right)=\left[\begin{array}{ll}a & b \\ c & d\end{array}\right]\left[\begin{array}{l}x \\ y\end{array}\right]+\left[\begin{array}{l}e \\ f\end{array}\right]$

The conversions to obtain the segments of the generator are given in Table 2. 
TABLE 2.

\begin{tabular}{|l|l|l|l|l|l|l|}
\hline \multirow{2}{*}{$\mathbf{W}$} & \multicolumn{4}{|l}{ Matrix } & \multicolumn{4}{l|}{} & \multicolumn{2}{l|}{ Translation } \\
\cline { 2 - 7 } & $\boldsymbol{a}$ & $\boldsymbol{b}$ & $\boldsymbol{c}$ & $\boldsymbol{d}$ & $\boldsymbol{e}$ & $\boldsymbol{f}$ \\
\hline 1 & 0.333 & 0.000 & 0.000 & 0.333 & 0.000 & 0.000 \\
\hline 2 & 0.333 & 0.000 & 0.000 & 0.333 & 0.000 & 0.333 \\
\hline 3 & 0.333 & 0.000 & 0.000 & 0.333 & 0.000 & 0.666 \\
\hline 4 & 0.333 & 0.000 & 0.000 & 0.333 & 0.333 & 0.000 \\
\hline 5 & 0.333 & 0.000 & 0.000 & 0.333 & 0.333 & 0.666 \\
\hline 6 & 0.333 & 0.000 & 0.000 & 0.333 & 0.666 & 0.000 \\
\hline 7 & 0.333 & 0.000 & 0.000 & 0.333 & 0.666 & 0.333 \\
\hline 8 & 0.333 & 0.000 & 0.000 & 0.333 & 0.666 & 0.000 \\
\hline
\end{tabular}

Here, W ( 1 to 8$)$ are set of linear relative changes. If $\mathrm{S}(0)$ is initial square than to $S(1)$ divide the $S(0)$ in nine and remove the interior of the center square, again to $S(2)$ subdivide each of the remaining eight square in nine squares and by removing the interior of the center square. Continue further to get next iterations

$S(0) \supset S(1) \supset S(2) \supset S(3) \supset \cdots \supset S(N)$

The similarity dimensions are deciphered as a measure of the space filling properties and multifaceted nature of the fractal shape. Accordingly, the fractal similarity dimension (d) is given by equation ( 7 ) for the proposed unit element.

$d=\frac{\log \left(\frac{\left(\frac{1}{n}\right)}{\log (r)}\right.}{\log \left(\frac{1}{8}\right)}=1.89279$

Here, $\mathrm{n}$ is non-overlapping copies of itself, which are eight in sierpinski carpet fractal and $\mathrm{r}$ is the scaling factor.

\subsection{Modelling of the CSCFA}

Using the obtained series of data points obtained from the process of simulation of antenna element in HFSS environment, mathematical modeling of the CSCFA is done using Curve-Fitting Method in MATLAB environment. In fact, curve-fitting method is used to analyze the best fit mathematical function to the obtained series of data points. In order to do so, numbers of options are available to fit data including Polynomial Fit, logarithmic fit, and Exponential Fit, etc. However, in the present work, Polynomial Curve Fitting method is employed to model return loss (S11) in terms of two separate geometrical dimensions including feed-position and feed width. Similarly, resonance frequency response is modeled with respect to patch-length of the simulated antenna. Accordingly, best suited equations obtained for the same are expressed mathematically as given below:

$\mathrm{F} 1=0.00000000013 \times \mathrm{L}^{4}+0.35 \times \mathrm{L}^{3}-8.9 \times \mathrm{L}^{2}+75 \times$ $\mathrm{L}-201.869$

$\mathrm{F} 2=0.06 \times \mathrm{L}^{2}-1.7 \times \mathrm{L}+17.26$

S11fp $=-0.3276 \times \mathrm{fp}^{3}+9.7 \times \mathrm{fp}^{2}-90 \times \mathrm{fp}+250$

$\mathrm{F} 3=-0.17 \times \mathrm{L}^{3}+4.2 \times \mathrm{L}^{2}-35 \times \mathrm{L}+105.695$

$\mathrm{S} 11 \mathrm{fw}=810 \times \mathrm{fw}^{3}-1100 \times \mathrm{fw}^{2}+470 \times \mathrm{fw}-90$

Here in equation (5) F1 represent the resonating frequency at $0^{\text {th }}$ iteration modeled in term of $\mathrm{L}$ that represent length of patch antenna and in equation (6) F2 represent the resonating frequency of patch antenna at $1^{\text {st }}$ iteration modeled in term of
L, similarly in equation (8) F3 represent the resonating frequency modeled in term of length of patch antenna at $2^{\text {nd }}$ iteration. S11 is corresponding return loss of antenna that is modeled in terms of feed position (fp) and feed width (fw). In the next section, the proposed antenna modeled by equation (5), (6), (7), (8) and (9) is optimized using Dragonfly Optimization method [15]. Dragonfly Optimization is used because it can perform better than other optimization techniques even with lesser number of parameters.

\subsection{Optimization of the CSCFA}

Dragonfly Optimization Method, introduced originally by S. Mirjalili in the year 2015 [15], imitates the static swarming as well as dynamic swarming behavior of dragonflies. In static swarming, dragonflies form small clubs and fly to and fro over a small area to hunt other flying preys. Local migration and sudden changes in the flying path are the main traits of a static swarming. In dynamic swarming, dragonflies form the swarm to migrate over a long distance in one direction. These two acts are similar to exploration and exploitation phase of other swarm inspired optimization techniques [15]. For updating the position of artificial dragonflies (search agents) in a search space and for simulating their movements, two vectors are considered-step $(\Delta \mathrm{X})$ and position $(\mathrm{X})$. The direction of shift of the dragonflies is shown by step vector $(\Delta \mathrm{X})$ and is defined in equation (10) as follows:

$\Delta \mathrm{X}_{\mathrm{k}+1}=\left(\mathrm{sS}_{\mathrm{j}}+\mathrm{aA}_{\mathrm{j}}+\mathrm{cC}_{\mathrm{j}}+\mathrm{fF}_{\mathrm{j}}+\mathrm{eE}_{\mathrm{j}}\right)+\mathrm{w} \Delta \mathrm{X}_{\mathrm{k}}$

where $w$ is the inertia weight of search agent, $S_{j}, A_{j}, C_{j}, F_{j}$, and $E_{j}$ indicates the separation, cohesion, alignment, food source and enemy of the $j^{\text {th }}$ individual respectively and $s, a, c, f$, and $e$ are separation, alignment, cohesion, food factor and enemy factor weights respectively. After calculating the step vector, the position vectors are computed by the following equation:

$\mathrm{X}_{\mathrm{k}+1}=\mathrm{X}_{\mathrm{k}}+\Delta \mathrm{X}_{\mathrm{k}+1}$

Where, $\mathrm{k}$ is the current iteration

To improve the randomness, stochastic behavior and exploration of the artificial dragonflies, the concept of random walk called levy flight is proposed in the work [15]. If search agent (Dragonfly) does not have a neighboring search agent, it will update its location by using Levy flight, with the following equation (12):

$\mathrm{X}_{\mathrm{k}+1}=\mathrm{X}_{\mathrm{k}}+\operatorname{Levy}(\mathrm{d}) \times \mathrm{X}_{\mathrm{k}}$

Based on above considerations, the Dragonfly Optimization Algorithm is executed in MATLAB using following fitness function for the modeled parameter of antenna, here equation (13) shows the fitness function to obtain desired resonance frequency that is used for equations (5), (6) and (8) at various stages of optimization process and equations (14) and (15) shows the fitness function to obtain good matching at various stages of optimization process which is used for equations (7) and (9) respectively for the optimization of simulated antenna:

Fitness function $1=(7.5-\mathrm{F})^{2}$

Fitness function $2=(17+\mathrm{S} 11 \mathrm{fp})^{2}$

Fitness function $3=(32.7676+\mathrm{S} 11 \mathrm{fw})^{2}$

Above Fitness Functions are applied in the Dragonfly Optimizer with the Parameters shown in Table 3. 
TABLE 3. Parameter Values for Dragonfly Optimizer and optimized patch length

\begin{tabular}{|l|l|l|l|l|l|}
\hline \multirow{2}{*}{$\begin{array}{l}\text { Parame } \\
\text { Name }\end{array}$} & \multicolumn{4}{|l|}{ Parameter Value in } \\
\cline { 2 - 6 } & Eq. (5) & Eq.(6) & Eq.(7) & Eq.(8) & Eq.(9) \\
\hline $\begin{array}{l}\text { Number of } \\
\begin{array}{l}\text { Search } \\
\text { Agents }\end{array}\end{array}$ & 100 & 100 & 100 & 100 & 100 \\
\hline $\begin{array}{l}\text { Lower } \\
\text { Bound }\end{array}$ & 8 & 7.5 & 6 & 7.5 & $\begin{array}{l}0.3 \\
\mathrm{~mm}\end{array}$ \\
\hline $\begin{array}{l}\text { Upper } \\
\text { Bound }\end{array}$ & 9 & 9 & 12.5 & 8.5 & $\begin{array}{l}0.76 \\
\mathrm{~mm}\end{array}$ \\
\hline $\begin{array}{l}\text { Dimensions } \\
\text { Max } \\
\text { Iterations }\end{array}$ & 1 & 1 & 1 & 1 & 1 \\
\hline $\begin{array}{l}\text { Optimized } \\
\text { Patch } \\
\text { Length }\end{array}$ & 8.6157 & 8.0 & 7.9694 & $\begin{array}{l}7.9008 \\
\mathrm{~mm}\end{array}$ & 0.6096 \\
$\mathrm{~mm}$
\end{tabular}

\subsection{Design of Proposed Fractal Antenna}

\section{Array}

The optimized CSCFA are configured suitably in the form of a $1 \times 2$ elements antenna array so as to reduce the effect of cross-coupling among the constituting members. The reduction in cross-coupling ensures improved performance of the proposed antenna array. Figure 2 shows the design of fractal antenna array using corporate feed. The optimized fractal antenna elements are configured suitably in the form of a $2 \times 2$ elements antenna array so as to reduce the effect of cross-coupling among the constituting members. The reduction in cross-coupling ensures improved performance of the proposed antenna array. Figure 3 shows the design of proposed fractal antenna array using corporate feed. All the dimensions of feeding structure are indicated in Figure 3 in the form of alphabets whose values are given in Table 4 .

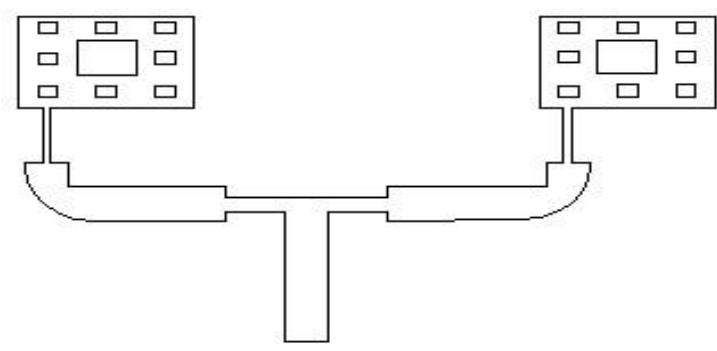

Fig 2: Design of 1x2 Element Fractal Antenna Array

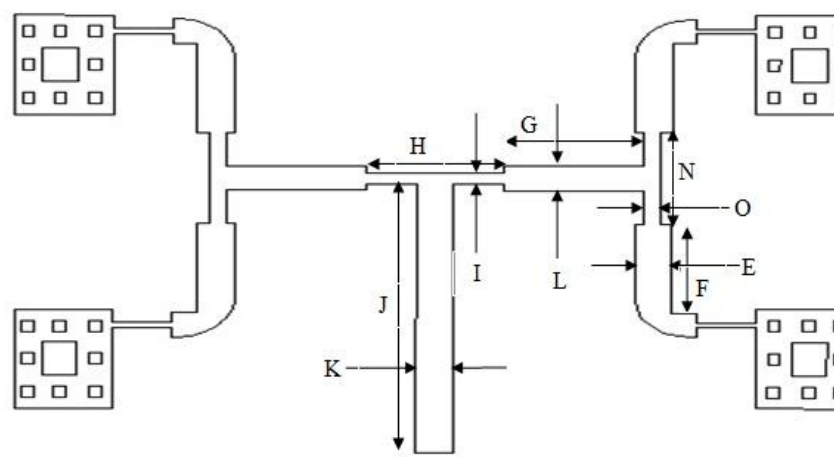

Fig 3: Proposed 2x2 Element Fractal Antenna Array
TABLE 4 Parametric value of Proposed Fractal Antenna Array

\begin{tabular}{|l|l|l|l|}
\hline Parameter & $\begin{array}{l}\text { Value } \\
(\mathbf{m m})\end{array}$ & Parameter & $\begin{array}{l}\text { Value } \\
(\mathbf{m m})\end{array}$ \\
\hline $\mathrm{K}, \mathrm{L}, \mathrm{E}$ & 3 & $\mathrm{G}$ & 11.3 \\
\hline $\mathrm{H}, \mathrm{N}$ & 11.2 & $\mathrm{~F}$ & 10.9858 \\
\hline $\mathrm{I}, \mathrm{O}$ & 1.3 & $\mathrm{~J}$ & 33.1512 \\
\hline
\end{tabular}

\section{RESULTS AND DISCUSSION}

We have made observation for different parameter of proposed unit cell antenna at various stage of design and simulation like gain, return loss, VSWR and bandwidth for the desired resonance frequencies before and after the optimization.

\subsection{Effect of Patch Length}

Patch length is inversely related to the resonance frequency of patch antenna and if there is a decrease in the length of patch antenna then resonance frequency will go up and vice-versa, a similar trend can be seen in the found results at various stages of designing and optimization of CSCFA in the present work, which is shown below in table 5. Best suited length for patch is found using DFO.

TABLE 5 Variation in frequency with length at different iterations with and without optimization

\begin{tabular}{|c|c|c|c|c|c|c|c|}
\hline P L & Fr & $\begin{array}{l}\text { I } \\
\text { No. }\end{array}$ & $\begin{array}{l}\text { Optimi } \\
\text { zation }\end{array}$ & R L & $\begin{array}{l}\text { VS } \\
\text { WR }\end{array}$ & G & BW \\
\hline 8.8846 & 7.3 & $0^{\text {th }}$ & No & -29.2 & 1.07 & 2.8 & 370 \\
\hline 8.6157 & 7.5 & $0^{\text {th }}$ & Yes & -31.32 & 1.05 & 3.04 & 400 \\
\hline 8.6157 & 7.1 & $1^{\mathrm{st}}$ & No & -16.7 & 1.34 & 2.2 & 330 \\
\hline 8 & 7.5 & $1^{\text {st }}$ & Yes & -17.3 & 1.31 & 2.9 & 338 \\
\hline 8 & 7.5 & $2^{\text {nd }}$ & No & -16.8 & 1.33 & 2.94 & 330 \\
\hline 7.9008 & 7.5 & $2^{\text {nd }}$ & Yes & -13.9 & 1.35 & 4.4 & 261 \\
\hline \multicolumn{4}{|c|}{$\begin{array}{l}\text { Fr - Resonance Frec } \\
(\mathrm{GHz}), \\
\text { RL- Return Loss }(\mathrm{dB}), \\
\text { G- Gain }(\mathrm{dB}),\end{array}$} & \multicolumn{4}{|c|}{$\begin{array}{l}\text { I No. - Iteration number } \\
\text { BW- Band width }(\mathrm{MHz}) \\
\text { PL- Patch Length }(\mathrm{mm})\end{array}$} \\
\hline
\end{tabular}

In figure 4 the variation of resonance frequency with length of patch is shown and using the data for which the graph is generated is used to model the length in terms of frequency using curve fitting and equation (8) is formulated after that DFO is applied on fitness function 1 for finding the optimized length for desired frequency $7.5 \mathrm{GHz}$. 


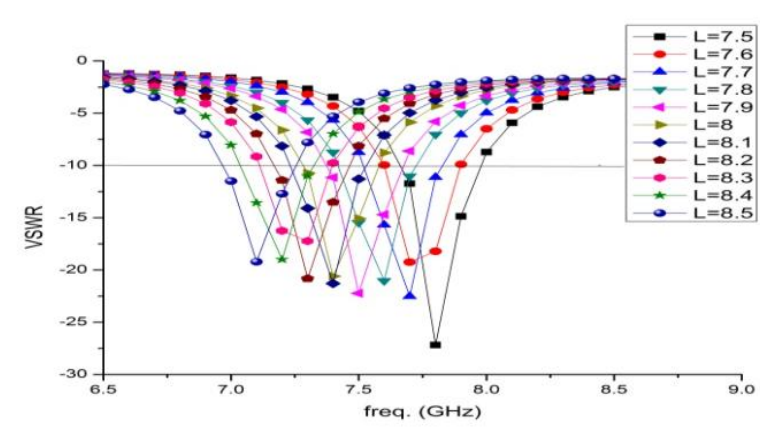

Fig 4: Variation of Resonance Frequency with Patch Length

\subsection{Effect of Quatrer Wave Transformer Position}

Quarter wave transformer width affects the return loss of the antenna, when matching is good between feed line and patch then return loss of the antenna is going to increase and also using DFO we have found a best position of quarter wave transformer where we found the multiband and that relflects from our simulation results as shown in Table 6 .

TABLE 6 Variation in the parameter of antenna with feed position

\begin{tabular}{|l|l|l|}
\hline & $\begin{array}{l}\text { Without } \\
\text { optimization }\end{array}$ & $\begin{array}{l}\text { With } \\
\text { optimization }\end{array}$ \\
\hline $\begin{array}{l}\text { Feed position } \\
(\mathrm{mm})\end{array}$ & 12.12 & 7.9694 \\
\hline Frequency (GHz) & 7.5 & $5.5,7.5,10$ \\
\hline Return loss & -13.9 & $\begin{array}{l}-22.7, \quad-22.6, \quad- \\
12.8\end{array}$ \\
\hline Bandwidth (MHz) & 261 & $191,306,231$ \\
\hline Gain (dB) & 4.4 & $1.7,4.2,3.3$ \\
\hline VSWR & 1.35 & $1.2,1.2,1.6$ \\
\hline
\end{tabular}

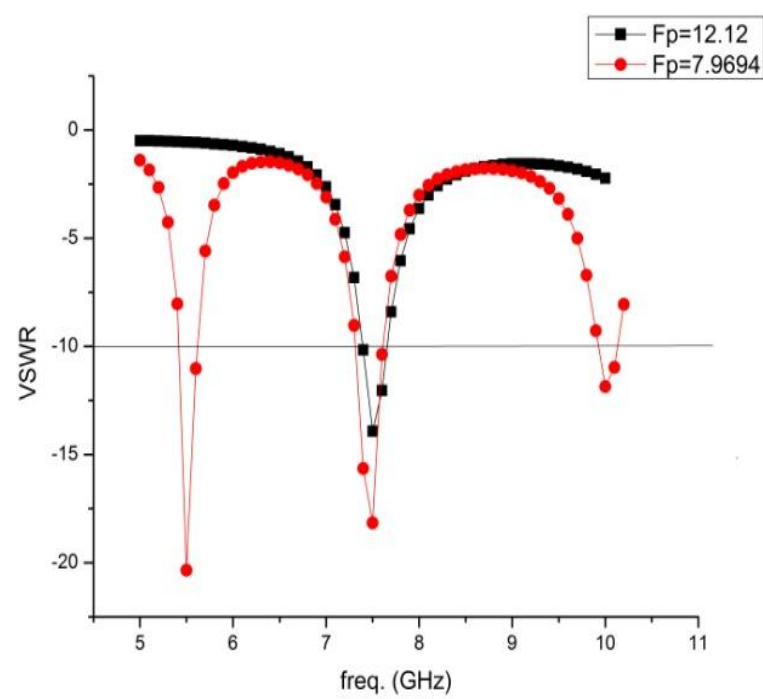

Fig. 5: Variation in resonance frequency with feed position
Table 6 and figure-5 shows the change in resonance frequencies for without optimized position and with optimized feed position and as we can see for optimized feed position we have obtained three resonance frequencies $5.5 \mathrm{GHz}$, $7.5 \mathrm{GHz}$ and $10 \mathrm{GHz}$. For finding the best suited feed position the feed position is modeled in terms of return loss (S11) and using fitness function 2 that is shown in equation (14) is optimized using DFO and the best suited position is obtained.

\subsection{Effect of Width of Quatrer Wave Transformer}

Table-7 and figure- 6 shows the change in return loss for different width of quarter wave transformer. For finding the best suited width, the width of quarter wave transformer is modeled in terms of return loss (S11) and using fitness function 3 that is shown in equation (15) is optimized using DFO and the best suited width is obtained and the result for optimized width is shown in Table-7.

TABLE 7 Variation in the parameter of antenna with feed position

\begin{tabular}{|l|l|l|}
\hline & $\begin{array}{l}\text { Without } \\
\text { optimization }\end{array}$ & $\begin{array}{l}\text { With } \\
\text { optimization }\end{array}$ \\
\hline $\begin{array}{l}\text { QWT width } \\
(\mathrm{mm})\end{array}$ & 0.76 & 0.6096 \\
\hline $\begin{array}{l}\text { Frequency } \\
(\mathrm{GHz})\end{array}$ & $5.5,7.5,10$ & $5.5,7.5,10$ \\
\hline Return loss & $-22.7,-22.6,-12.8$ & $-19.3,-32.2,-13.5$ \\
\hline $\begin{array}{l}\text { Bandwidth } \\
\text { (MHz) }\end{array}$ & $191,306,231$ & $176,300,258$ \\
\hline Gain (dB) & $1.7,4.2,3.3$ & $1.7,4.3,3.7$ \\
\hline VSWR & $1.2,1.2,1.6$ & $1.2,1.0,1.5$ \\
\hline
\end{tabular}

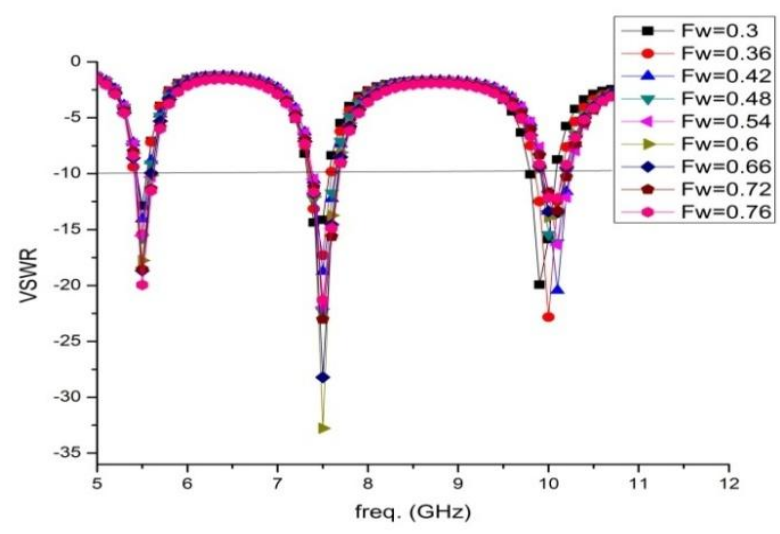

Fig. 6: Variation in return loss with quarter wave transformer width

The performance parameters like Bandwidth, efficiency, Return Loss, VSWR and gain of the simple CRMPA and final optimized CSCFA with modified feed position are tabulated in Table-8. Figure-8 shows the return loss and Figure-9 shows the VSWR for the final optimized CSCFA and it is reflecting clearly that results are quite promising. 


\subsection{Performance of the $1 \times 2$ Element Antenna Array}

Figure- 8 shows the return loss and Figure-9 shows the VSWR response for the designed array and the results also shown in tabular form in the comparison of single fractal element antenna in table 8 which shows a good improvement in different performance parameters. The radiation pattern for the designed $1 \times 2$ array is shown in figure-7. E-plane and $\mathrm{H}$ plane pattern are shown in figure-7(a), 7(b) and in 7(c) at $5.6 \mathrm{GHz}, 7.5 \mathrm{GHz}$ and at $9.9 \mathrm{GHz}$ respectively which shows that at all the three resonating frequencies the array is omnidirectional in H-plane.

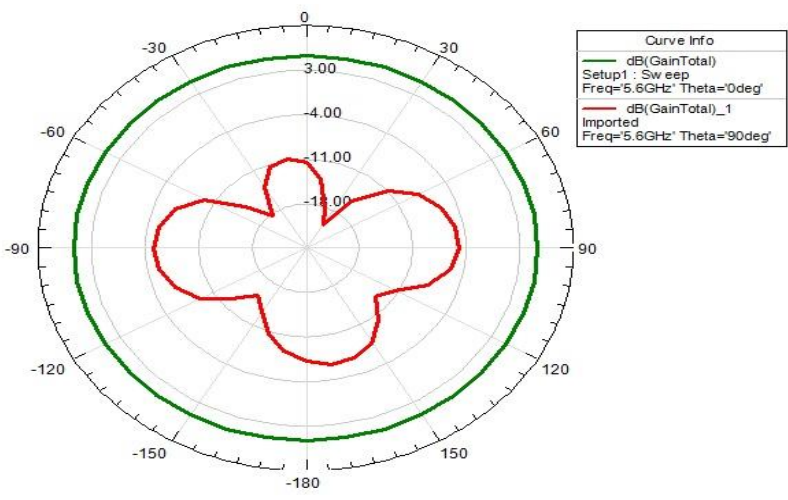

Figure 7(a)

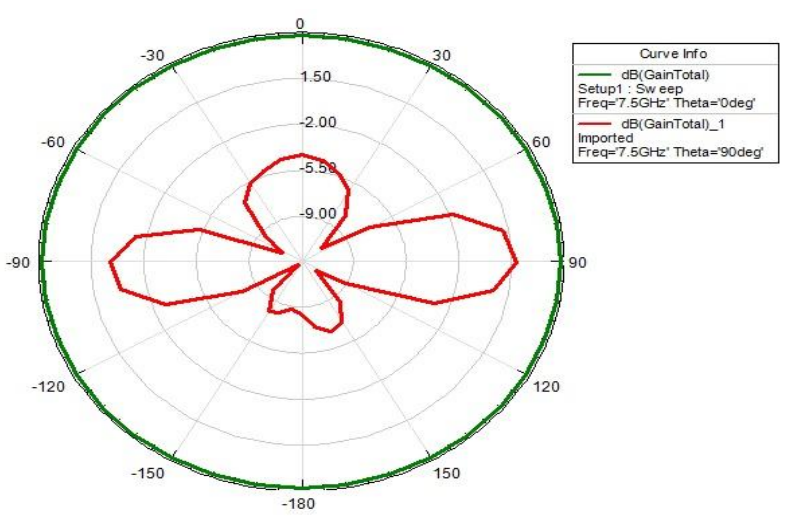

Figure 7(b)

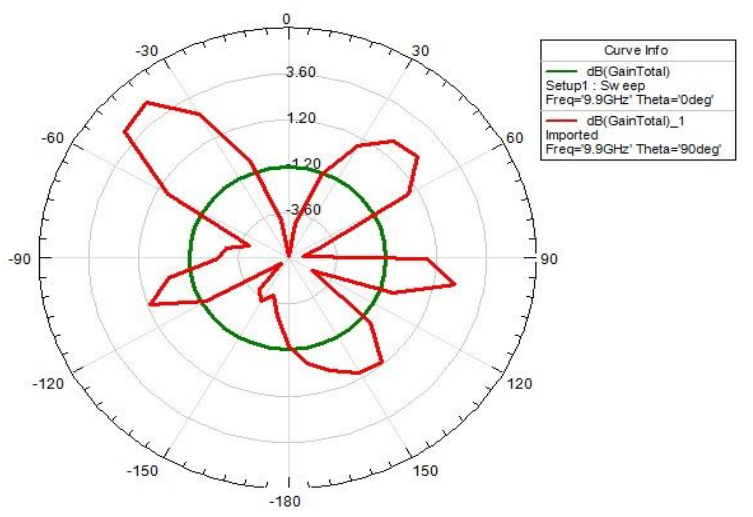

Figure 7(c)

Fig. 7: E-plane and H-plane Radiation Patterns at (a) $5.6 \mathrm{GHz},($ b) $7.5 \mathrm{GHz}$ and (c) $9.9 \mathrm{GHz}$

\subsection{Performance of the Proposed $2 \times 2$ Element Antenna Array}

Figure- 8 shows the return loss and Figure-9 shows the VSWR response for the proposed designed array and the results also shown in tabular form in the comparison of optimized CSCFA in table 8 which shows a good improvement in different performance parameters. The radiation pattern for the designed $2 \times 2$ array is shown in Figure-10. E-plane and $\mathrm{H}$ plane pattern are shown in figure 10(a), 10(b) and in 10(c) at $5.6 \mathrm{GHz}, 7.4 \mathrm{GHz}$ and at $10.7 \mathrm{GHz}$ respectively which shows that at all the three resonating frequencies the array is omnidirectional in H-plane.

TABLE-8 Parameters of CRMPA, optimized CSCFA, 1x2 Fractal Antenna Array and Proposed 2x2 Element Fractal Antenna Array

\begin{tabular}{|l|l|l|l|l|}
\hline & CRMPA & $\begin{array}{l}\text { Optimized } \\
\text { CSCFA }\end{array}$ & $\begin{array}{l}\text { 1x2 } \\
\text { Element } \\
\text { Antenna } \\
\text { Array }\end{array}$ & $\begin{array}{l}\text { 2x2 } \\
\text { Element } \\
\text { Proposed } \\
\text { Fractal } \\
\text { Antenna } \\
\text { Array }\end{array}$ \\
\hline $\begin{array}{l}\text { Resonant } \\
\text { (GHz) }\end{array}$ & 7.5 & 5.5, & 5.6, & 5.6, \\
& & 7.5, & 7.5, & 7.4, \\
\hline $\begin{array}{l}\text { Return } \\
\text { loss (S11) }\end{array}$ & -21.2 & 10 & 9.9 & 10.7 \\
\hline Gain (dB) & 4.3 & -19.3, & -18.7, & -14.2, \\
& & -32.2, & -26.8, & -20.8, \\
& & -13.5 & -17.1 & -12 \\
\hline $\begin{array}{l}\text { Bandwidth } \\
\text { (MHz) }\end{array}$ & 323 & 1.7, & 5.28, & 5.3, \\
& & 3.3, & 6.67, & 6.4, \\
& & 300, & 415, & 470, \\
VSWR & 1.3 & 258 & 241 & 883 \\
\hline & & 1.2, & 1.26, & 1.4, \\
& & 1.5 & 1.09, & 1.2, \\
& & & 1.32 & 1.6 \\
\hline
\end{tabular}




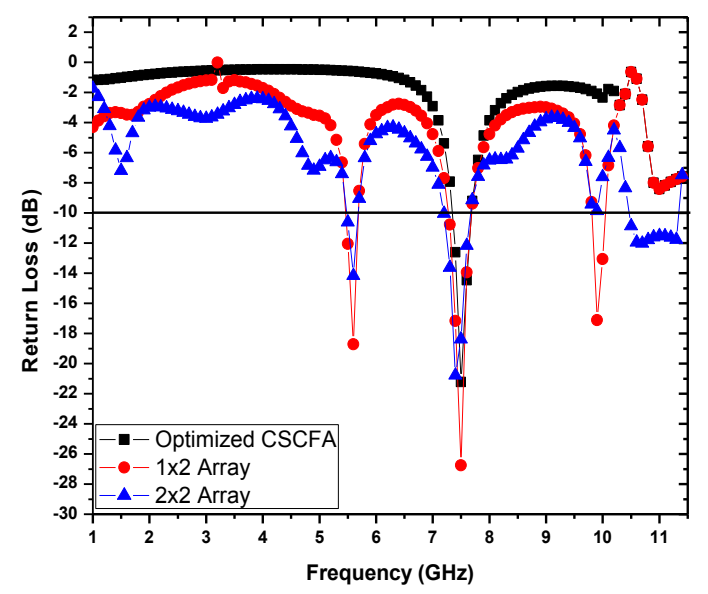

Fig. 8: Return loss for optimized CSCFA, $1 \times 2$ antenna array and $2 \times 2$ antenna array

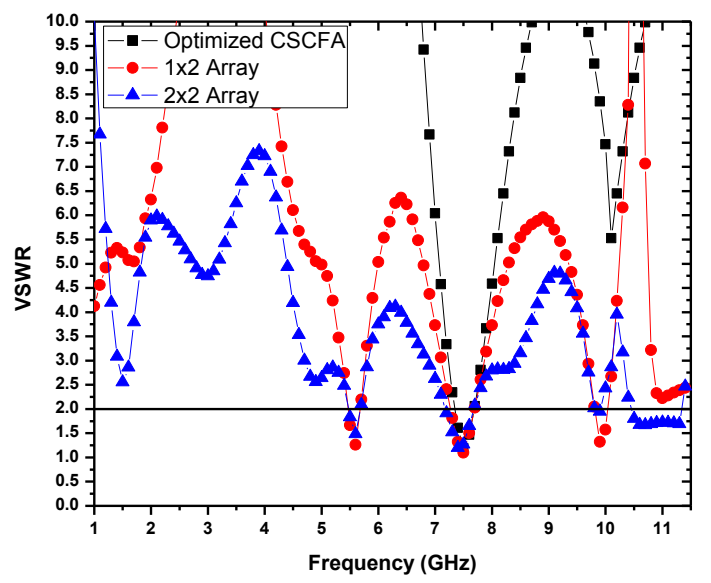

Fig. 9: VSWR of optimized CSCFA, $1 \times 2$ Antenna Array and Proposed $2 \times 2$ Fractal Antenna Array

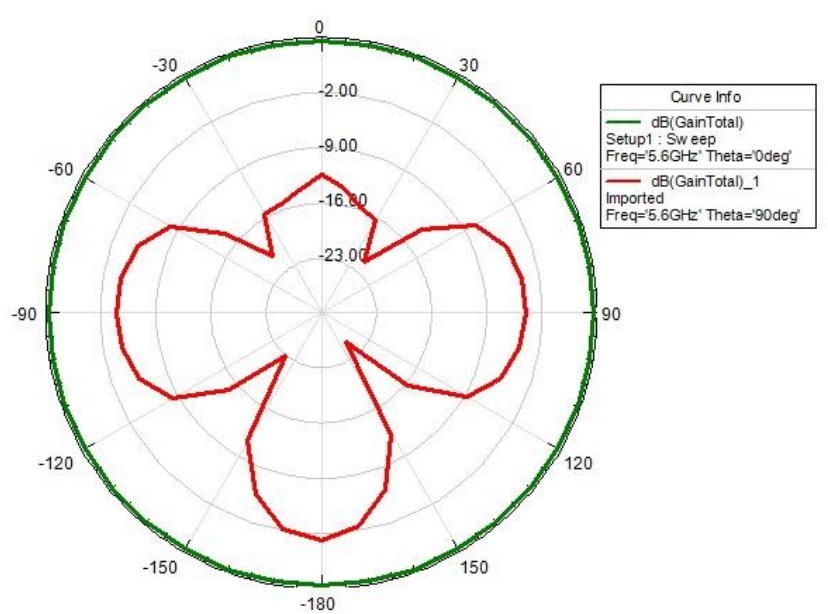

(a)

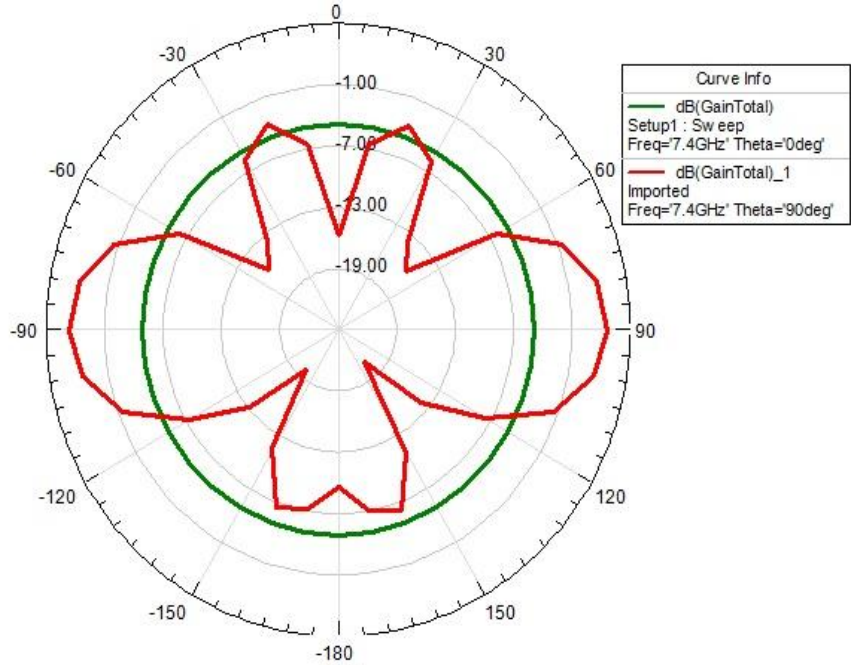

(b)

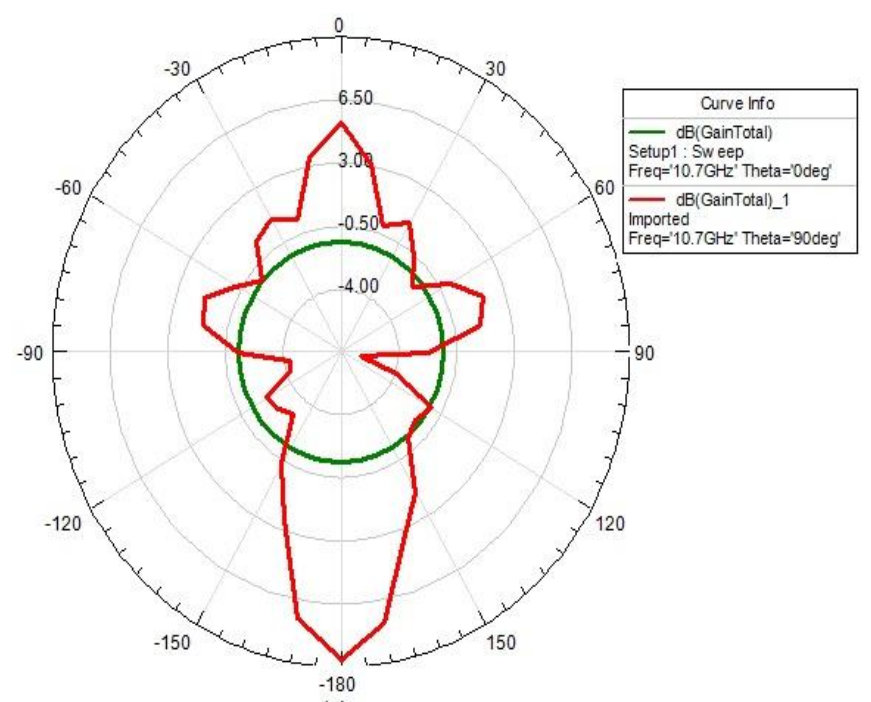

(c)

Fig. 10: E-plane and H-plane Radiation Patterns at (a) $5.6 \mathrm{GHz},(\mathrm{b}) 7.4 \mathrm{GHz}$ and (c) $10.7 \mathrm{GHz}$

\section{CONCLUSION}

Sierpinski Fractal Antenna Array with $2 \times 2$ element configuration is designed for fixed satellite communication as well as Maritime radio navigation with enhanced performance in terms of gain, return loss and bandwidth The proposed Fractal Antenna Array is designed on the architecture of an optimized CSCFA Element incorporated with modified position of the feed. Dragonfly optimization executed in combination with polynomial curve fitting method is proved to be an effective alternative for the optimization of microstrip patch antennas. The results show that the proposed array of $2 \times 2$ resonates very effectively at $5.6 \mathrm{GHz}, 7.4 \mathrm{GHz}$ and 10.7 $\mathrm{GHz}$ frequency with an achievement of $202 \mathrm{MHz}, 470 \mathrm{MHz}$, and $883 \mathrm{MHz}$ bandwidths respectively for the specified bands. The novelty of the present work lies in the design of the proposed antenna array with enhanced performance for two separate applications including fixed-satellite communication as well as maritime radio-navigation. Moreover, successful use of Dragonfly Optimization in the present work in achieving three different optimized geometrical dimensions of the unit element in the proposed antenna array establishes its effectiveness for the design of such antennas. However, such 
an attempt has not been reported in the literature so far. Accordingly, in line with this strategy, the work is under further progress to develop multi-element Fractal Antenna System using Sirpinksi Fractal Carpet Geometry. The proposed optimization technique will have promising future in the design of microstrip patch antennas using different fractal geometries.

\section{ACKNOWLEDGMENT}

The authors express sincere thanks to the Faculty and Staff of the ECE Department at SLIET, Longowal for making the Laboratory Facilities available for the present work.

\section{REFERENCES}

[1] P. Bhartia, I. Bahl, A. Ittipiboon R. Garg, Microstrip Antenna Design Handbook.: Artech House, 2001.

[2] Rafal Przemvcki, Leszek Nowosielski, and Kazimierz Piwowarczyk Marek Bugai, "Analysis different methods of microstrip antennas feeding for their electrical parameters," in PIER Proceedings , Kuala Lumpur, 2012.

[3] Dundesh S. Kamshetty, Suresh L. Yogi Mahesh M. Gadag, "Design of different feeding techniques of rectangular microstrip antenna for $2.4 \mathrm{GHz}$ RFID applications using IE3D," in Proceeding of the international conference on advances in computer, electronics and electrical engineering.

[4] Jagat Singh Gurdeep Singh, "Comparative Analysis of microstrip patch antenna with different feeding techniques," in International conference on recent advances and future trends in information technology, 2012.

[5] C A. Balanis, Antenna Theory: Analysis and Design. New York: John Wiley \& Sons Inc, 1997.

[6] Thomas A. Milligan, Modern Antenna Design. Hoboken, New Jersey: John Wiley \& Sons Inc, 2005.

[7] Vishnu Prakash and Raju Srinivasan P. Jothilakshmi, "Miniaturised multiband two element coaxial continuous transverse stub antenna for satellite C-band applications," IET Microwaves, Antenna \& Propagation, vol. 8, no. 7, pp. 474-481, 2014.
[8] A Vimala Juliet, M. Florence Silvia and G. B. V. Sai Krishna G. Jegan, "Novel design and performance analysis of rectangular frequency reconfigurable microstrip patch antenna using line feed technique for wireless applications," Indian Journal of Science and Technology, vol. 9, no. 29, August 2016.

[9] Nitika Rani, Amarveer Singh, Vatanjeet Singh, Ranjeet Kaur, and Ekambir Singh Jasleen Kaur, "Design and performance analysis of high gain flexible Yagi microstrip patch antenna for fixed satellite, radio location and amateur-satellite service applications," Progress in electromagnetics research, pp. 948-952, May 2017.

[10] C. H. Huang, and C. C. Hong S. M. Yang, "Design and analysis of microstrip antenna arrays in composite laminated substrates," Journal of Electromagnetic Analysis and Applications, pp. 115-124, 2014.

[11] Santanu Kumar Behera Yogesh Kumar Choukiker, "Modified Sierpinski square fractal antenna covering ultra-wide band application with band notch characteristics," IET Microwaves, Antennas \& Propagation, vol. 8, no. 7, pp. 506-512, 2014.

[12] Shahryar Shafique Qureshi, Khalid Mahmood, Mehr-eMunir and Sajid Nawaz Khan Saad Hassan Kiani, "TriBand Fractal Patch Antenna for GSM and Satellite Communication systems," International Journal of Advanced Computer science and Apllications, pp. 182186, 2016.

[13] D. M. Pozar and B. Kaufman, "Design Consideration for Low Sidelobe Microstrip Arrays," IEEE Transactions on Antenna and Propagation, 1176-1185 1990.

[14] D. Orban and G. J. K. Moernaut, "The basics of antenna arrays", Orban Microwave Products (2018, Feb) Orbanmicrowave.co.[Online]. http://orbanmicrowave.com/the-basic-of-antenna-arrays/

[15] S. Mirjalili, "Dragonfly algorithm: A new meta-heuristic optimization technique for solving single-objective, discrete, and multi-objective problems," Neural Computing and Applications, Springer, pp. 1-21, 2015. 